Original Research Article

\title{
Analysis of drug promotional literature and its abidance to WHO guidelines
}

\author{
Meenakshi Jindal, Priya Choudhary*, Rajeev K. Sharma
}

Department of Pharmacology, Muzaffarnagar Medical College Muzaffarnagar, Uttar Pradesh, India

Received: 05 September 2019

Revised: 06 October 2019

Accepted: 10 October 2019

*Correspondence to:

Dr. Priya Choudhary,

Email: choudharypp@ gmail.com

Copyright: (C) the author(s), publisher and licensee Medip Academy. This is an openaccess article distributed under the terms of the Creative Commons Attribution NonCommercial License, which permits unrestricted noncommercial use, distribution, and reproduction in any medium, provided the original work is properly cited.

\begin{abstract}
Background: Drug promotional literature (DPL) is used by the pharmaceutical companies for promotion of their drug. It is the commonest source for providing information about the drug to the physician. According to WHO promotional literature should be reliable, truthful, informative, balanced and up to date.

Methods: Study was conducted in Department of Pharmacology, Muzaffarnagar Medical College. 200 drug promotional literatures like advertisements published in medical journal, package insert of medicinal products and brochures were collected and analysed according to WHO criteria. Results: Total 200 promotional literatures were analysed. 100 promotional literatures were from the medical journal, 50 were package inserts of medicinal products and 50 were medicinal brochures. On assessing DPL using WHO criteria, all DPL mentioned brand names and dosage form (100\%). Most of them published the generic name $(98.5 \%)$, therapeutic uses $(78 \%)$, side- effects $(75 \%)$, dosage regimen $(70 \%)$, contraindication $(62.5 \%)$, warnings $(55 \%)$, drug interaction $(54 \%)$, precaution $(50 \%)$, reference to scientific literature $(45 \%)$, name of manufacture and distributor $(99 \%)$, address of manufacturer and distributor $(50 \%)$. Out of 200 DPL only 151 DPL contain references to scientific literature, 88 DPL references were retrievable and 63 were non retrievable.

Conclusions: Our study shows although pharmaceutical companies are trying to adhere to the WHO criteria it is not fulfilled. As DPL are an important source of seeking information by the medical practitioner who rely on them to impart treatment to the patient, strict steps to regulate fulfilment of the WHO criteria should be taken by the government and authorities.
\end{abstract}

Keywords: Drug promotional literatures, Package inserts, Medicinal brochures

\section{INTRODUCTION}

Drugs are regularly prescribed by physicians to treat the diseases. Most of these drugs are manufactured by pharmaceutical companies and they provide the information through drug promotional literature (DPL). DPL could be in the form of package inserts / medical advertisement in various journals/ medical brochures. According to the World Health Organization (WHO) "all informational and persuasive activities by manufactures and distributors, the effect of which is to induce the prescription, supply, purchase, and/or use of medicinal drugs" comes under definition of drug promotional literature. $^{1,2}$ DPL is an important source of seeking information by the busy medical practitioner. Physician targeted promotion through medical representatives is one of the most common tactic for drug promotion by pharmaceutical drug companies. ${ }^{3}$ All promotion making claims concerning medicinal drugs should be reliable, accurate, truthful, informative, balanced, up-to-date, and capable of substantiation. They should not contain any misleading or unverifiable statements or omissions likely to induce medically unjustifiable drug use or to give rise to undue risks. ${ }^{4}$ Numerous studies have shown that the literature is persuasive in nature rather than educational. ${ }^{5}$ DPL includes product characteristics, side effects, dosage regime, contraindications and various marketing claims with references which at times, may be inadequate, 
deceptive and of poor educational value. These lapses in the field of ethics are a matter of immense concern for the past few decades. DPL provided by the pharmaceutical companies cannot be entirely relied upon for being disseminating drug information for their own interest, still they tends to have a powerful impact on physicians prescribing behaviour. ${ }^{6}$

Various studies have demonstrated that printed drug promotional materials distributed by the pharmaceutical companies are often biased. ${ }^{7}$ Lack of time to access medical literature further complicate the way in to impartial drug information in developing countries. ${ }^{8}$ In today's era, with the discovery of newer generations of therapeutic agents, prescribing physicians need to keep themselves updated with the ever changing scientific knowledge of medicines. Various claims have been quoted in the drug promotional advertisements and references are also provided to increase their credibility and authenticity.

However, a grey zone has always been there for manipulation by the pharmaceutical industry because of the dearth of standard recommendations for it in India. It is essential to sensitize the medical fraternity and educate them regarding the harmful nature of unethical drug promotion. They should be trained to critically analyse drug advertisements and other promotional materials. We believe these initiatives could be quite helpful to sensitize the future prescribers on drug promotion. This study aims to create awareness of the credibility, reliability and authenticity of the drug promotional literatures among the prescribers, which are tactically given to them by the medical representatives. With this background, the present study was conducted with the primary objectives of comparing the drug promotional literature of different pharmaceutical companies on the basis of WHO guidelines on ethical drug promotion.

\section{METHODS}

It is a prospective, observational and cross sectional study conducted in the pharmacology department of Muzaffarnagar Medical College. The study was conducted during December 2018 to August 2019 collecting Drug promotional literature like advertisement published in various medical journals like JAMA, Indian J Paediatr, package insert of medicinal products and brochures.200 promotional literatures were analysed according to the WHO criteria for drug promotion. Drug advertisements related to medical equipment, devices, Ayurvedic medicines, nutritional supplements were excluded.

We assessed all the collected material by using WHO criteria which included the name of the active ingredients either their international non-proprietary name or approved generic name, brand name, pharmacological data, dosage form or regimen, approved therapeutic uses, side-effects, warning, precautions, drug interaction, contraindication, special situation, name and address of manufacture, and references. ${ }^{9}$ Collected data was entered in a Microsoft Excel sheet and results were expressed as percentages.

\section{RESULTS}

Total 200 promotional literature were analysed. 100 promotional literatures were from the medical journal, 50 were package inserts of medicinal products and 50 were medicinal brochures. Out of 200 promotional literature 125 promotional literature advertise single drug formulation and 75 were for fixed dose combination. DPL were collected from all the systems like CVS, endocrinology, antimicrobials, CNS, G.I.T, Autocoids, ANS, blood, vaccine, vitamins and minerals, diuretics, miscellaneous.

Table 1: The system wise number and percentage of drug promotional literature assessed.

\begin{tabular}{|lll|}
\hline $\begin{array}{l}\text { System wise distribution } \\
\text { of DPL }\end{array}$ & Number & $\begin{array}{l}\text { Percentage } \\
(\%)\end{array}$ \\
\hline DPL of CVS & 30 & 15 \\
\hline DPL of endocrinology & 35 & 17.5 \\
\hline DPL of antimicrobials & 25 & 12.5 \\
\hline DPL of CNS & 25 & 12.5 \\
\hline DPL of GIT & 15 & 7.5 \\
\hline DPL of autocoids & 20 & 10 \\
\hline DPL of ANS & 10 & 5 \\
\hline DPL of blood & 8 & 4 \\
\hline DPL of vaccines & 8 & 4 \\
\hline Vitamins and minerals & 8 & 4 \\
\hline Diuretics & 4 & 2 \\
\hline Miscellaneous & 7 & 3.5 \\
\hline
\end{tabular}

Table 2: Analysis of drug promotional literature using WHO criteria.

\begin{tabular}{|ll|}
\hline WHO criteria & $\begin{array}{l}\text { Number of DPL in } \\
\text { compliance and \% }\end{array}$ \\
\hline Brand name & $200(100)$ \\
\hline Generic name & $197(98.5)$ \\
\hline $\begin{array}{l}\text { Other ingredient known to } \\
\text { cause problems }\end{array}$ & $04(2)$ \\
\hline Dosage forms & $200(100)$ \\
\hline Dosage regimen & $140(70)$ \\
\hline Therapeutic uses & $156(78)$ \\
\hline Side-effects & $150(75)$ \\
\hline Precautions & $100(50)$ \\
\hline Contraindications & $125(62.5)$ \\
\hline Warnings & $110(55)$ \\
\hline Drug interactions & $108(54)$ \\
\hline $\begin{array}{l}\text { Reference to scientific } \\
\text { literature }\end{array}$ & $90(45)$ \\
\hline $\begin{array}{l}\text { Name of manufacturer and } \\
\text { distributor }\end{array}$ & $198(99)$ \\
\hline $\begin{array}{l}\text { Address of manufacturer and } \\
\text { distributor }\end{array}$ & $100(50)$ \\
\hline
\end{tabular}


On assessing DPL using WHO criteria as shown in table 2, all DPL mentioned brand names and dosage form $(100 \%)$. Most of them published the generic name (98.5\%), therapeutic uses (78\%), side-effects (75\%), dosage regimen $(70 \%)$, contraindication $(62.5 \%)$, warnings $(55 \%)$, drug interaction $(54 \%)$, precaution $(50 \%)$, reference to scientific literature $(45 \%)$, name of manufacture and distributor (99\%), address of manufacturer and distributor (50\%). Out of 200 DPL only 151 DPL contain references to scientific literature. Out of 200 DPL only 90 DPL gave references, Out of 90 only 48 references of the medical journal and package inserts were retrievable and 42 were non retrievable.

\section{DISCUSSION}

Scientific, correct, unbiased information on benefits and risks of drugs provided in DPLs is crucial to physicians in order to determine the most appropriate treatment for patients. Clinicians have to keep themselves well informed about the hundreds of new drugs entering the market every year. For this, they often have to depend on the drug promotional material by the pharmaceutical companies. DPL is considered as a good source of information about new drugs coming in the market. Hence, pharmaceutical companies should provide accurate, adequate, balanced, and valid information to a clinician.

In our study, cardiovascular agents, antidiabetic drugs, and antimicrobials were among the top three groups of drugs being promoted, indicating that pharmaceutical companies are targeting diseases which are widely prevalent. $200 \mathrm{DPL}$ were assessed according to WHO criteria, all DPL mentioned brand names and dosage form $(100 \%)$. Most of them published the generic name (98.5\%), therapeutic uses (78\%), side- effects $(75 \%)$, dosage regimen (70\%), contraindication (62.5\%), warnings $(55 \%)$, drug interaction $(54 \%)$, precaution $(50 \%)$, reference to scientific literature $(45 \%)$, name of manufacture and distributor (99\%), address of manufacturer and distributor (50\%). Out of 200 DPL only 90 DPL contain references to scientific literature. Out of 90 DPL only 48 DPL references of the medical journals and package inserts were retrievable and 42 were non retrievable. All the brochures were colourful and attractive, but had irrelevant pictures related to the drugs being promoted. DPLs had used nonspecific representations occupying major area, which could have been utilized appropriately for listing various properties of drugs, other studies have reported similar finding.

In our study majority of DPLs had provided brand name, generic name, similar to Indian study conducted by Tayade and Kulkarni. ${ }^{10}$ Almost $50 \%$ of the DPLs did not contain adequate information on the pharmacological effects and mechanism of action which was similar to the study published by Hoovinahole, Kamath. ${ }^{11}$ In our study the dosage regimen percentage was $70 \%$ better than Ikwadi, who claim it to be $59.25 \%$, it may because shagupta assessed only 81 DPL. ${ }^{12}$ We compared our study with study of Ganashree $\mathrm{P}$, the percentage of DPL showing therapeutic uses $78 \%$ vs $96.5 \%$, side effects $75 \%$ vs $32 \%$, precautions $50 \%$ vs $32.5 \%$, contraindication $62.5 \%$ vs $34 \%$, drug interaction $54 \%$ Vs $29 \%$ name of drug manufacture $99 \%$ vs $97 \% .^{13}$ on comparison we found that DPL which we assessed had better percentage of side effects, precautions, contraindication and drug interaction so this shows that pharmaceutical companies are now aware of WHO criteria and are trying to follow them.

In our study, we have seen that standard pharmaceutical companies had tried to follow the WHO guidelines but there are companies who need to be aware of these guidelines because they are making DPL for financial benefits and persuasive for clinicians. As DPL plays utmost importance source of drug information to the treating physician and critically evaluate patient on basis of the drug information so it become important to follow the established guidelines of WHO. Regional Ethics Committee in various metropolitan cities in India collect complaints about unethical drug promotion and report the same to the Drug Controller General of India to take necessary legal steps to regulate pharmaceutical companies to publish DPLs fulfilling the WHO criteria.

\section{CONCLUSION}

Our study shows pharmaceutical companies are trying to adhere the WHO criteria but all the criteria are not fulfilled completely. As the DPL are an important source of seeking information by the busy medical practitioner and they rely on them to impart the treatment to the patient so strict legal steps to regulate pharmaceutical companies to publish DPLs fulfilling the WHO criteria should be taken by the government.

\section{Funding: No funding sources \\ Conflict of interest: None declared \\ Ethical approval: Not required}

\section{REFERENCES}

1. Jadav SS, Dumatar CB, Dikshit RK. Drug promotional literatures (DPLs) evaluation as per World Health Organisation (WHO) criteria. J App Pharm Sci. 2014;4:84-8.

2. Rohra DK, Gilani AH, Memon IK, Perven G, Khan MT, Zafar H, et al. Critical evaluation of the claims made by pharmaceutical companies in drug promotional material in Pakistan. J Pharm Pharm Sci. 2006;9:50-9.

3. Mikhael EM. Evaluating the reliability and accuracy the promotional brochures for the genetic pharmaceutical companies Iraq using WHO guidelines. J Pharma Bioall Sci. 2015;7:65-8.

4. Ethical criteria for medicinal drug promotion. World Health Organization (Online). 1988. Available at: 
http://apps.who.int/medicinedocs/documents/whozi0 8e/whozip08e.pdf. Assessed on 10th May 2017.

5. Brunton LL, Chabner BA, Knollmann BC. Goodman and Gilman's.The pharmacological basis of therapeutics, McGraw- Hill Companies; 12th edition, 2012.

6. Chitnis K, Limaye A, Bhosale M. Pharmaceutical promotional literature: Opinions of physicians in a tertiary care hospital in Mumbai. Int $\mathbf{J}$ Basic Clin Pharmacol. 2013;2:541-7.

7. Randhawa GK, Singh NR, Rai J, Kaur G, Kashyap R. A critical analysis of claims and their authenticity in Indian drug promotional advertisements. Adv Med. 2015;469147.

8. Subish P, Mishra P, Shankar PR, Bista D, Purwar B. Contribution of the regional drug information center towards drug safety-an experience from Western Nepal. J Nep Med Assoc. 2006;45:216-8.

9. Ethical criteria for medicinal drug promotion. World Health Organ (online) 1988;13:1-22. Available at: http://www.who.int/medicinedocs/collect/edmweb/pd f/whozip08e. Assessed on 10th May 2017.
10. Tayade MC, Kulkarni NB. Accuracy of the drug advertisements in medical journals in India. J Clin Diagn Res. 2011;5:583-5.

11. Hoovinahole S, Kamath A. A study of adherence of drug promotional literatures from various clinical specialties to the World Health Organization ethical criteria for drug promotion. J Pharm Negative Results. 2016;7(1):37-41.

12. Naikwadi AS, Jadhav BR, Patil PP. Critical Analysis of Indian Drug Promotional Literature (DPL) using WHO criteria for Ethical Medicinal Drug Promotion. IOSR J Dent Med Sci. 2017;16(9):49-54.

13. Ganashree P, Bhuvana K, Sarala N. Critical review of drug promotional literature using the World Health Organization guidelines. J Res Pharm Pract. 2016;5(3):162-5.

Cite this article as: Jindal M, Choudhary P, Sharma RK. Analysis of drug promotional literature and its abidance to WHO guidelines. Int J Basic Clin Pharmacol 2019;8:2502-5. 